\title{
The clinical relevance of glycobiology
}

\author{
Harry Schachter
}

Commentary

See related articles, pages 1613-1619

and 1687-1695.

Department of Structural Biology and Biochemistry, The Research Institute,

The Hospital for Sick Children, 555 University Avenue, Department of Biochemistry, University of Toronto,

Toronto, Ontario M5G 1X8, Canada. Phone: (416) 813-5915; Fax: (416) 813-5022; E-mail: harry@sickkids.on.ca.

J. Clin. Invest. 108:1579-1582 (2001). DOI:10.1172/JCI200114498.

The study of protein-bound glycans dates back to the 19th century (1). Until recently these macromolecules have played second fiddle to their cousins, the nucleic acids and proteins. This is not surprising in view of the stunning advances during the second half of the 20th century in the DNA-RNA-protein paradigm, which Francis Crick called the Central Dogma. Since information transfer is a key ingredient of this dogma, it is relevant to point out that the diversity of linkages and branching patterns between monomer building blocks confers on carbohydrates the ability to carry an enormous amount of information in very compact structures (2). These structures therefore carry "more information bang for the buck" than do the other, simpler polymers. The cell surface is covered with protein- and lipid-bound glycans. These structures vary significantly between cell types and at different stages of mammalian development and probably play important roles in the interaction of a cell with its cellular and fluid environment (3-5). Glycoproteins and proteoglycans are essential for normal development in mice (6-16), Drosophila melanogaster (17-20), and Caenorhabditis elegans (18, 21-26). Table 1 lists mice with null mutations in genes required for glycosylation; other null mutant mice are described in reviews by Stanley (9) and Varki and Marth (11).

In spite of all the evidence showing the importance of glycans for metazoan development, glycobiology did not earn the respect it deserves until the recent description of several human congenital diseases with defects in the glycosylation of proteins (27-32). Since at least $0.5-1 \%$ of the transcribed human genome is devoted to the production of proteins involved in the synthesis, degradation, and function of glycoconjugates (11), it is likely that we have seen only the tip of the iceberg. Two papers in this issue of the JCI (Schenk et al., ref. 33; and Kranz et al., ref. 34) support this suggestion. These papers describe a congenital disorder of glycosylation (CDG) in which the defective gene encodes an unusual protein with a role in glycan synthesis that is not as clearly defined as were the defects in the previously described human CDGs shown in Table 2.

\section{Congenital disorders of glycosylation}

The CDGs (previously known as carbohydrate-deficient glycoprotein syndromes) are a group of congenital diseases, often with severe multisystemic defects, characterized by defective $N$ glycosylation. The papers in this issue describe four unrelated patients with a new variant of CDG group I (CDG-If). Group I CDGs involve deficiencies in the assembly of the dolichylpyrophosphate-linked oligosaccharide $N$-glycan precursor (Figure 1) and/or its transfer to asparagine residues on the nascent polypeptide (35). Since complete loss of $N$-glycosylation is lethal in both yeast and mammals, all CDG-I patients have "leaky" mutations. This is indicated by the presence of appreciable amounts of $\mathrm{Glc}_{3} \mathrm{Man}_{9} \mathrm{GlCNAc}_{2}$-pyrophosphate-dolichol (Figure 1) in the cells of all CDG-I patients. The four CDG-If patients all show severe psychomotor retardation, seizures, and other multisystemic abnormalities consistent with CDG-I. The serum transferrin isoelectric focusing patterns are similar to the pattern observed in most CDG-I patients. However, the major abnormal dolichol pyrophos-

Table 1

Glycosylation-deficient mutant mice that show developmental abnormalities

Missing enzyme

$\beta 1,2-G l c N A c-t r a n s f e r a s e ~ I$

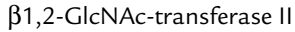

$\beta 1,6$-GlcNAc-transferase V

Dol-P GlcNAc-1-phosphate transferase

Ser/Thr O-GlcNAc-transferase

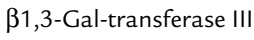

$\alpha 3,6$-mannosidase II
Biochemical role

Addition of GlcNAc to the Man $\alpha 1-3$ arm of the complex $\mathrm{N}$-glycan core Addition of GlcNAc to the Man $\alpha 1-6$ arm of the complex $N$-glycan core Addition of GlcNAc to the Mano1-6 arm of the complex $N$-glycan core Transfers GlcNAc-1-phosphate to Dol-P to make GlcNAc-PP-Dol Adds GlcNAc in O-glycosidic linkage to Ser/Thr of many intracellular proteins Adds Gal to GlcNAc-R; homologue of Drosophila Brainiac

Removes 2 Man residues from $\mathrm{GlcNAc}_{1} \mathrm{Man}_{5} \mathrm{GlcNAc}_{2}$-Asn-X
Phenotype

References

Mice cannot make complex $\mathrm{N}$-glycans.

Embryonic-lethal at embryonic days 9-10

Perinatal lethality; a few survivors

(about 1\%) mimic CDG-Ila (see Table 2)

Viable mice. Suppression of

tumor growth and metastasis

Mice cannot make any LLOs.

Embryonic-lethal at embryonic days 4-5

Deletion of this X-linked gene causes

loss of embryonic stem cell viability

Embryonic lethality prior to implantation

Defective synthesis of complex $N$-glycans

Mimics congenital dyserythropoietic

anemia type II (HEMPAS)

Causes autoimmune disease (see Table 2)

7,8
6
10
12
13
14

15,16

HEMPAS, hereditary erythroblastic multinuclearity with a positive acidified serum lysis test. 
Table 2

Human congenital disorders with defective glycosylation

(1) CDG Group I: Defects in N-linked protein glycosylation due to deficiencies in the assembly of the dolichylpyrophosphate-linked oligosaccharide and/or its transfer to asparagine residues on the nascent polypeptides.

\begin{tabular}{|c|c|c|c|c|c|}
\hline CDG type & Enzyme defects & Gene & $\mathrm{OMIM}^{\mathrm{A}}$ & Locus Link ${ }^{A}$ & Acronym \\
\hline la & Phosphomannomutase 2 & PMM2 & $\begin{array}{l}212065 \\
601785\end{array}$ & 5373 & CDG-la \\
\hline $\mathrm{Ib}$ & Phosphomannose isomerase & $M P I$ & $\begin{array}{l}602579 \\
154550\end{array}$ & 4351 & CDG-Ib \\
\hline Ic & $\begin{array}{l}\text { Dolichyl-P-Glc:Man }{ }_{9} G \mathrm{GlNAc}_{2} \text {-PP-dolichyl } \\
\alpha 1,3 \text {-Glucosyltransferase }\end{array}$ & ALG6 & $\begin{array}{l}603147 \\
604566\end{array}$ & 29929 & CDG-Ic \\
\hline Id & $\begin{array}{l}\text { Dolichyl-P-Man:Man }{ }_{5} \mathrm{GlcNAc}_{2} \text {-PP-dolichyl } \\
\alpha 1,3-\text { Mannosyl-transferase }\end{array}$ & $\begin{array}{l}\text { ALG3 } \\
\text { NOT56L }\end{array}$ & 601110 & 10159 & CDG-Id \\
\hline le & Dolichol-P-Man synthase 1 & $D P M 1$ & 603503 & 8813 & CDG-le \\
\hline If & Dolichol-P-Man utilization defect 1; Lec35 & MPDU1 & 604041 & 9526 & CDG-If \\
\hline Ix & Genetic basis unknown & & $\begin{array}{l}603585 \\
212067\end{array}$ & & CDG-Ix \\
\hline \multicolumn{6}{|c|}{ (2) CDG group II: Defects in the processing of $\mathrm{N}$-glycans or addition of other glycans to proteins. } \\
\hline CDG type & Enzyme defect & Gene & OMIM $^{\mathrm{A}}$ & Locus Link ${ }^{\mathrm{A}}$ & Acronym \\
\hline Ila & $\begin{array}{l}\text { UDP-GIcNAc: } \alpha 6 \text {-D-mannoside } \beta 1,2- \\
N \text {-acetylglucosaminyltransferase II (GnT II) }\end{array}$ & MGAT2 & $\begin{array}{l}212066 \\
602616\end{array}$ & 4247 & CDG-Ila \\
\hline IIb & $\alpha 1,2$-Glucosidase I & GCS1 & 601336 & 7841 & CDG-IIb \\
\hline Illc & GDP-fucose transporter I & FUCT1 & $\begin{array}{l}266265 \\
605881\end{array}$ & 55343 & $\begin{array}{l}\text { CDG-Ilc } \\
\text { LAD II }\end{array}$ \\
\hline \multicolumn{6}{|l|}{ (3) Other. } \\
\hline Name of disease & Enzyme defect & Gene & $\mathrm{OMIM}^{\mathrm{A}}$ & Locus Link ${ }^{\mathrm{A}}$ & Acronym \\
\hline HEMPAS & 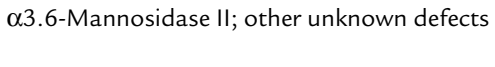 & MAN2A & $\begin{array}{l}224100 \\
154582\end{array}$ & 4124 & CDA II \\
\hline
\end{tabular}

AOMIM, Online Mendelian Inheritance in Man; Locus Link summarizes all the known information on a particular gene. Both databases can be accessed at http://www.ncbi.nlm.nih.gov/. LAD II, leukocyte adhesion deficiency type II. CDA II, congenital dyserythropoietic anemia type II.

phate oligosaccharides (lipid-linked oligosaccharides; LLOs) in the patient fibroblasts are $\mathrm{Man}_{5} \mathrm{GlcNAc}_{2}$ (Figure 1c) and $\mathrm{Man}_{9} \mathrm{GlcNAc}_{2}$ (Figure 1b), a novel pattern suggesting defects in both dolichol phosphate mannosedependent (Dol-P-Man-dependent) mannosylation and dolichol phosphate glucose-dependent (Dol-PGlc-dependent) glucosylation, respectively. Surprisingly, the two dolichol phosphate monosaccharide precursor synthases and the respective glycosyltransferases are all normal. In fact, whereas all five of the previously described CDG-I types (CDG-Ia to -Ie) are due to defects in enzymes within the synthetic pathways that lead to $\mathrm{Glc}_{3} \mathrm{Man}_{9} \mathrm{GlcNAc}_{2}$-pyrophosphatedolichol, the mechanism of action of the protein $(\mathrm{Lec} 35 \mathrm{p})$ responsible for CDG-If has not yet been determined.
The name Lec35 derives from a lectin-resistant Chinese hamster ovary (CHO) mutant cell line that accumulates $\mathrm{Man}_{5} \mathrm{GlcNAc}_{2}$-pyrophosphatedolichol (Figure 1c) (36). The Lec35 protein was shown to be required for the utilization of both Dol-P-Man and Dol-P-Glc and, consequently, for the mannosylation and glucosylation of LLOs, the mannosylation of glycosylphosphatidylinositols, the $C$-man-

\section{Figure 1}

(a) The structure of $\mathrm{Glc}_{3} \mathrm{Man}_{9} \mathrm{GlcNAc}_{2}$-pyrophosphatedolichol. This compound is essentially the only LLO found in normal human fibroblasts. However, appreciable amounts of this material are also found in all CDG-I fibroblasts reflecting the "leaky" nature of the mutations in these patients. Based on animal studies, total lack of this LLO is not compatible with life. (b) The structure of $\mathrm{Man}_{9} \mathrm{GlcNAc}_{2}$-pyrophosphate-dolichol. This is one of the major LLOs found in CDG-If. The accumulation of this compound implies a defect in the addition of Glc in $\alpha 1,3$ linkage to the Man at the arrow. Since the synthesis of Dol-P-Glc and the activity of the relevant Dol-PGlc-dependent $\alpha 1$,3-glucosyltransferase are both normal in CDG-If, the defect has been attributed to an inability to utilize Dol-P-Glc. (c) The structure of $\mathrm{Man}_{5} \mathrm{GlcNAc}_{2}-$ pyrophosphate-dolichol. This is the other major LLO found in CDG-If. The accumulation of this compound implies a defect in the addition of four Man residues to the Man at the arrow by four Dol-P-Man-dependent mannosyltransferases. Since the synthesis of Dol-P-Man and the activities of the relevant mannosyltransferases are normal in CDG-If, the defect has been attributed to an inability to utilize Dol-P-Man.

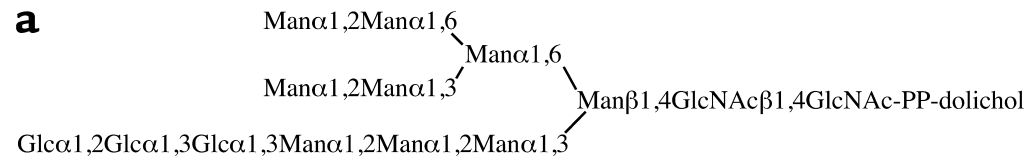

b

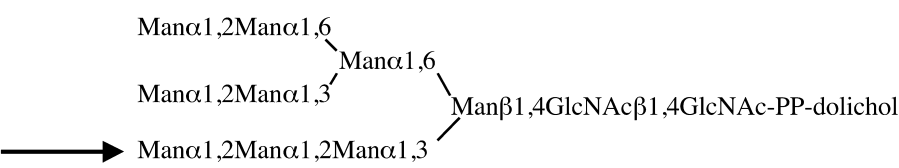

C

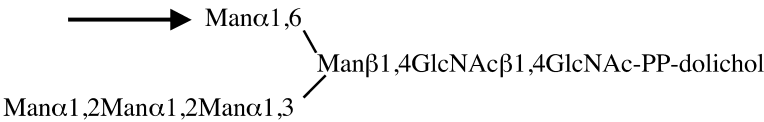


nosylation of tryptophanyl residues, and protein $O$-mannosylation (37). These results show that Lec35p has an essential role for all known classes of dolichol phosphate monosaccharidedependent glycosyltransferase reactions in mammals. The human Lec35 ortholog has been named MPDU1 (mannose phosphate dolichol utilization defect 1) and was mapped to 17p12-13. Sequence analysis of the MPDU1 gene showed distinct mutations in all four CDG-If patients. The predicted amino acid sequence of Lec35p does not suggest an obvious function or mechanism. Lec35p is a $27-\mathrm{kDa}$ endoplasmic reticulum membrane-associated protein with two putative transmembrane segments and is probably involved in the "flipping" of Dol-P-Man and Dol-P-Glc from the cytoplasm, where these molecules are synthesized, to the lumen of the endoplasmic reticulum, where glycosylation occurs. The use of mutant mammalian cell lines (such as lectinresistant $\mathrm{CHO}$ lines) and yeast mutants has been essential for the elucidation of many CDG types, including CDG-If.

\section{Phenotypic variability among the CDG individuals}

The complexity of the various glycosylation pathways suggests that many congenital diseases of unknown etiology will turn out to be CDGs. One major reason is the diversity of clinical presentation and severity in the CDG spectrum. This is true even in a single type of CDG (for example, the four cases of CDG-If described in this issue of the JCI [refs. 33, 34]). The same diversity occurs in the broader spectrum of CDG-I even though all known types are due to defective synthesis of $\mathrm{Glc}_{3} \mathrm{Man}_{9} \mathrm{Glc}$ $\mathrm{NAc}_{2}$-pyrophosphate-dolichol. For example, the enzymes responsible for CDG-Ia (phosphomannomutase 2) and CDG-Ib (phosphomannose isomerase) sit side by side in the synthetic pathway leading to Dol-P-Man, yet the clinical presentations of the two diseases differ enormously: CDG-Ia patients show severe psychomotor retardation, whereas CDG-Ib patients have no neurological defects. The biochemical findings within a single CDG type also tend to vary; for example, the lipid- and protein-bound oligosaccharide patterns can differ quite dramatically between patients. This is perhaps not surprising in view of the various deglycosylation and reglycosylation pathways involved (38-40). There are almost certainly other as-yet unknown factors - genetic, regulatory, environmental, etc. - that contribute to differences between CDG patients (28). Both under- and overglycosylation may cause disease, and it may be necessary to strike a healthy balance between the two (28). The relative frequency of certain CDG mutant alleles suggests that they may have advantages in the heterozygous state, e.g., protection against viral infection (28).

The search for new CDG types can benefit from animal models, which may show phenotypic changes that differ from the human clinical presentations. Indeed, comparison of Tables 1 and 2 shows that only two known mouse glycosylation defects correspond to identified human CDGs, namely CDG-IIa and the atypical CDG HEMPAS (hereditary erythroblastic multinuclearity with a positive acidified serum lysis test). Hence, there are almost certainly more CDGs to be described, and clinicians should think of CDG whenever they are faced with a puzzling congenital disease. Of the human diseases, only CDG-Ib and -IIc have, to date, responded to therapy oral mannose and fucose, respectively. Further research may improve this picture as it reveals more fascinating facts about glycobiology.

1. Montreuil, J. 1995. The history of glycoprotein research: a personal view. In Glycoproteins. Volume 29a, New Comprehensive Biochemistry. J. Montreuil, J.F.G. Vliegenthart, and H. Schachter, editors. Elsevier Science. Amsterdam, The Netherlands. 1-12.

2. Laine, R.A. 1994. A calculation of all possible oligosaccharide isomers both branched and linear yields $1.05 \times 10^{12}$ structures for a reducing hexasaccharide: the Isomer Barrier to development of single-method saccharide sequencing or synthesis systems. Glycobiology. 4:759-767.

3. Fukuda, M. 2000. Cell surface carbohydrates: cell type-specific expression. In Molecular and cellular glycobiology. Volume 30, Frontiers in Molecular Biology. M. Fukuda and O. Hindsgaul, editors. Oxford University Press. Oxford, United Kingdom. 1-61.

4. Homeister, J.W., and Lowe, J.B. 2000. Carbohydrate recognition in leukocyte-endothelial cell interactions. In Molecular and cellular glycobiology. Volume 30, Frontiers in Molecular Biology. M. Fukuda and O. Hindsgaul, editors. Oxford University Press. Oxford, United Kingdom. 62-115

5. Brusés, J.L., and Rutishauer, U. 2000. Polysialic acid in neural cell development: roles, regulation and mechanism. . In Molecular and cellular glycobiol ogy. Volume 30, Frontiers in Molecular Biology. M. Fukuda and O. Hindsgaul, editors. Oxford University Press. Oxford, United Kingdom. 116-132.

6. Wang, Y., et al. 2000. Investigating a model of human CDG type II reveals a heterogenic disease with cell type-specific defects and frequent perinatal lethality. Glycobiology. 10:1131-1132.

7. Metzler, M., et al. 1994. Complex asparaginelinked oligosaccharides are required for morphogenic events during post-implantation development. EMBO J. 13:2056-2065.

8. Ioffe, E., and Stanley, P. 1994. Mice lacking Nacetylglucosaminyltransferase I activity die at mid-gestation, revealing an essential role for complex or hybrid N-linked carbohydrates. Proc. Natl. Acad. Sci. USA. 91:728-732.

9. Stanley, P. 2000. Functions of carbohydrates revealed by transgenic technology. In Molecular and cellular glycobiology. Volume 30, Frontiers in Molecular Biology. M. Fukuda and O. Hindsgaul, editors. Oxford University Press. Oxford, United Kingdom. 169-198.

10. Granovsky, M., et al. 2000. Suppression of tumor growth and metastasis in Mgat5-deficient mice. Nat. Med. 6:306-312.

11. Varki, A., and Marth, J. 1995. Oligosaccharides in vertebrate development. Seminars in Developmen tal Biology. 6:127-138.

12. Marek, K.W., Vijay, I.K., and Marth, J.D. 1999. A recessive deletion in the GlcNAc-1-phosphotransferase gene results in peri-implantation embryonic lethality. Glycobiology. 9:1263-1271.

13. Shafi, R., et al. 2000. The O-GlcNAc transferase gene resides on the $\mathrm{X}$ chromosome and is essential for embryonic stem cell viability and mouse ontogeny. Proc. Natl. Acad. Sci. USA. 97:5735-5739.

14. Vollrath, B., Fitzgerald, K.J., and Leder, P. 2001. A murine homologue of the Drosophila brainiac gene shows homology to glycosyltransferases and is required for preimplantation development of the mouse. Mol. Cell. Biol. 21:5688-5697.

15. Chui, D., et al. 1997. Alpha-mannosidase-II deficiency results in dyserythropoiesis and unveils an alternate pathway in oligosaccharide biosynthesis. Cell. 90:157-167.

16. Chui, D., et al. 2001. Genetic remodeling of protein glycosylation in vivo induces autoimmune disease. Proc. Natl. Acad. Sci. USA. 98:1142-1147.

17. Selleck, S.B. 2000. Proteoglycans and pattern formation. Sugar chemistry meets developmental genetics. Trends Genet. 16:206-212.

18. Selleck, S.B. 2001. Genetic dissection of proteoglycan function in Drosophila and C. elegans. Semin. Cell Dev. Biol. 12:127-134.

19. Bruckner, K., Perez, L., Clausen, H., and Cohen, S 2000. Glycosyltransferase activity of Fringe modulates Notch-Delta interactions. Nature. 406:411-415.

20. Moloney, D.J., et al. 2000. Fringe is a glycosyltransferase that modifies Notch. Nature. 406:369-375.

21. Herman, T., and Horvitz, H.R. 1999. Three proteins involved in Caenorhabditis elegans vulval invagination are similar to components of a glycosylation pathway. Proc. Natl. Acad. Sci. USA. 96:974-979.

22. Bulik, D.A., et al. 2000. $s q v-3,-7$, and -8 , a set of genes affecting morphogenesis in Caenorhabditis elegans, encode enzymes required for glycosaminoglycan biosynthesis. Proc. Natl. Acad. Sci. USA. 97:10838-10843.

23. Okajima, T., Yoshida, K., Kondo, T., and Furukawa, K. 1999. Human homolog of Caenorhabditis elegans sqv-3 gene is galactosyltransferase I involved in the biosynthesis of the glycosaminoglycan-protein linkage region of proteoglycans. J. Biol. Chem. 274:22915-22918.

24. Culetto, E., and Sattelle, D.B. 2000. A role for Caenorhabditis elegans in understanding the function and interactions of human disease genes. Hum. Mol. Genet. 9:869-877.

25. Chen, S., Spence, A.M., and Schachter, H. 2000 Phenotypes of Caenorhabditis elegans UDP-Glc NAc:alpha-3-D-mannoside beta-1,2- $N$-acetylglucosaminyltransferase I (GnT I) null mutants. Glycobiology. 10:1114. (Abstr.)

26. Berninsone, P., Hwang, H.Y., Zemtseva, I., 
Horvitz, H.R., and Hirschberg, C.B. 2001. SQV-7, a protein involved in Caenorbabditis elegans epithelial invagination and early embryogenesis, transports UDP-glucuronic acid, UDP-N-acetylgalactosamine, and UDP-galactose. Proc. Natl. Acad. Sci. USA. 98:3738-3743.

27. de Lonlay, P., et al. 2001. A broad spectrum of clinical presentations in congenital disorders of glycosylation I: a series of 26 cases. J. Med. Genet. 38:14-19.

28. Freeze, H.H., and Westphal, V. 2001. Balancing Nlinked glycosylation to avoid disease. Biochimie. 83:791-799.

29. Jaeken, J., and Carchon, H. 2000. What's new in congenital disorders of glycosylation? Europ. J. Paediatr. Neurol. 4:163-167.

30. Schachter, H., editor. 1999. Molecular basis of glycoconjugate disease. Biochim. Biophys. Acta. Volume 1455. Elsevier Science. Amsterdam, The Netherlands. 61-420.
31. Montreuil, J., Vliegenthart, J.F.G., and Schachter, H., editors. 1996. Glycoproteins and disease. Volume 30, New comprehensive biochemistry. Elsevier Science. Amsterdam, The Netherlands. 1-486.

32. Schachter, H. 2001. Congenital disorders involving defective $\mathrm{N}$-glycosylation of proteins. Cell. Mol. Life Sci. 58:1085-1104.

33. Schenk, B., et al. 2001. MPDU1 mutations underlie a novel human congenital disorder of glycosylation, designated type If. J. Clin. Invest. 108:1687-1695.

34. Kranz, C. 2001. A mutation in the human MPDU1 gene causes congenital disorder of glycosylation type If (CDG-If). J. Clin. Invest. 108:1613-1619.

35. Aebi, M., et al. 2000. Letter to the Glyco-Forum Carbohydrate-deficient glycoprotein syndromes become congenital disorders of glycosylation: an updated nomenclature for CDG. Glycobiology. 10:iii-v.
36. Camp, L.A., Chauhan, P., Farrar, J.D., and Lehrman, M.A. 1993. Defective mannosylation of glycosylphosphatidylinositol in Lec35 Chinese hamster ovary cells. J. Biol. Chem. 268:6721-6728.

37. Anand, M., et al. 2001. Requirement of the Lec35 gene for all known classes of monosaccharide-Pdolichol-dependent glycosyltransferase reactions in mammals. Mol. Biol. Cell. 12:487-501.

38. Spiro, R.G. 2000. Glucose residues as key determinants in the biosynthesis and quality control of glycoproteins with $\mathrm{N}$-linked oligosaccharides. J. Biol. Chem. 275:35657-35660.

39. Herscovics, A. 2001. Structure and function of Class I alpha1,2-mannosidases involved in glycoprotein synthesis and endoplasmic reticulum quality control. Biochimie. 83:757-762.

40. Parodi, A.J. 2000. Protein glucosylation and its role in protein folding. Annu. Rev. Biochem. 69:69-93. 